\title{
Atividades Lúdicas no Ensino de Processos de Software
}

\author{
Adriano Bessa Albuquerque
}

Universidade de Fortaleza (UNIFOR)

Av. Washington Soares, 1321 - Bl J S1 30 - 60.811-341 - Fortaleza - Ce - Brasil

adriano.ba@terra.com.br

\begin{abstract}
The education of Software Engineering at the universities is of fundamental importance for the training of professionals, becoming them well qualified and able to aggregate on the software organizations which they work. This is important, especially, when we consider the large opportunities and the high level of competitiveness of the market. However, when teaching knowledge related to software process, the transfer of information is no more sufficient, requiring the utilization of practical activities that can consolidate the content presented. This paper presents a playful experience at the University of Fortaleza, when were performed practical lessons, using legos, covering five processes of the MPS.BR.
\end{abstract}

Resumo. O ensino de Engenharia de Software nas Universidades é de fundamental importância para a formação de profissionais bem qualificados e capazes de agregar com qualidade nas organizações de software em que trabalham, considerando as oportunidades e o alto nível de competitividade do mercado. No entanto, em relação ao ensino de processos de software, apenas o repasse de informações não é suficiente, exigindo atividades práticas que possam consolidar os conteúdos apresentados. Este artigo apresenta uma experiência lúdica na Universidade de Fortaleza, utilizando legos, onde foram realizadas aulas práticas abordando cinco processos do MPS.BR.

\section{Introdução}

Os recursos humanos podem ser considerados os ativos mais valiosos nestes tempos onde o conhecimento é a matéria prima capaz de incrementar os negócios das organizações. Uma empresa pode estar bem organizada, com suas estratégias estabelecidas, ter processos bem definidos e implementados, porém, sem pessoas que possam desempenhar com qualidade suas atividades diárias, o futuro desta empresa está comprometido.

No entanto, percebe-se que nos dias atuais, confunde-se bastante o ter acesso rápido a informações com o refletir e compreender. Negligencia-se cada vez mais o posicionar-se de forma reflexiva diante das informações recebidas e das experiências vivenciadas na rotina diária.

Popper (1996), um dos maiores defensores da análise crítica, ressaltou a importância que tem para o desenvolvimento do ser humano, o ato de refletir sobre nossas experiências, destacando, principalmente, a relevância de experimentarmos as nossas hipóteses, utilizando o método de tentativa e eliminação dos erros. 
Diante deste contexto, este artigo apresenta a experiência de aulas de engenharia de software, abordando conteúdos relacionados a cinco processos de software do MPS.BR (SOFTEX, 2007), onde foi utilizada uma abordagem lúdica, utilizando legos, para possibilitar os alunos vivenciarem situações, de forma que os conteúdos, até então apresentados, fossem melhor compreendidos.

A seção 2 apresenta a importância de abordagens lúdicas para a compreensão de conteúdos. A seção 3 apresenta o relato da experiência da nova abordagem e a seção 4 apresenta a análise dos resultados obtidos. Finalmente, a seção 5 apresenta as considerações finais e os trabalhos futuros.

\section{O Lúdico em Prol do Conhecimento e da Compreensão}

De acordo com o dicionário filosófico de Mora (1991) conhecer é o ato pelo qual um sujeito apreende um objeto, de forma que este objeto passa a estar no sujeito de forma representativa. Além disso, quando o sujeito o representa tal como o objeto é, significa que o sujeito tem um conhecimento verdadeiro (embora possivelmente parcial) do objeto.

Vários autores (Popper, 1972, Dewey, 1979, Moles, 1998) abordaram o fato da apreensão dos objetos da realidade estar fortemente relacionada ao cabedal de conceitos adquiridos pelo sujeito e às suas experiências vivenciadas e refletidas. Portanto, a teoria é capaz de ampliar as possibilidades de nossa vida prática, que por sua vez permite testar e avaliar as nossas, até então, consideradas verdades.

De acordo com Popper (1972), uma teoria é um instrumento que submetemos a prova pela aplicação e que julgamos, quanto à capacidade, pelos resultados das aplicações. Daí a relevância da aplicação de conceitos a partir de vivências.

Corroborando, ainda, com a necessidade de serem realizadas experiências no processo educacional, Dewey (1979), colocou que toda a história científica da humanidade demonstra não haver condições para uma atividade mental completa, quando nos conformamos em sermos meros observadores passivos, sendo necessário promover, convenientemente, atividades em que se possam manipular instrumentos da realidade.

No entanto, pode-se experimentar uma realidade de diversas formas, podendo ir da realização de um experimento científico a um jogo em que os participantes têm objetivos e devem se guiar por regras pré-estabelecidas. Uma das principais vantagens do jogo, enquanto instrumento pedagógico, está no fato de que em qualquer jogo são construídos e definidos um conjunto de conceitos e de significações, que são mais facilmente compreendidos pelos participantes, visto que a atividade lúdica, por não ser tão rígida e formal, permite uma maior abertura para lidar com o novo, o inesperado e dificuldades. Além disso, em qualquer jogo observa-se um maior livre trânsito das idéias.

Dewey (1979) foi um dos autores que destacou a importância das atividades lúdicas (brinquedos, jogos, entre outras) no auxílio da apreensão da realidade. Segundo o autor, no momento em que as coisas ficam sendo sinais, no momento em que adquirem uma capacidade representativa, isto é, a de fazer as vezes de outras coisas, o 
brinquedo, de mera exuberância física que era, transforma-se em atividade que comporta um fator mental.

Ele enfatizou, ainda, que no brincar, os significados se tornam conhecimentos familiares, assim como também se organizam, se agrupam e se ligam por conexões. Além disso, segundo Dewey (1979), o ritmo, a competição e a cooperação, que fazem parte da maioria dos brinquedos e jogos, também trazem consigo o senso de organização.

Em relação às atividades lúdicas, vale ressaltar, ainda, que apesar do jogo ser uma atividade relacionada à não-seriedade, ao livre, à voluntariedade, ele é de suma importância para a cultura de qualquer povo e o desenvolvimento dos seus cidadãos (HUIZINGA, 1980).

\section{Ensinando Processos de Software de Forma Lúdica}

A motivação para utilizar este tipo de abordagem, visando a consolidação de conteúdos explicados em sala de aula, veio de uma experiência na RioSoft em 2004, onde o autor deste artigo, na época aluno de doutorado da COPPE, juntamente com um aluno de mestrado utilizaram quebra-cabeças em um curso abordando a área de processo "Foco de Processo Organizacional" do CMMI para profissionais de várias empresas cariocas.

$\mathrm{Na}$ avaliação do curso realizada pelos treinandos, a metodologia foi muito elogiada e os dois instrutores perceberam o seguintes ganhos: (i) os conceitos foram mais bem comprendidos; (ii) a aula tornou-se menos cansativa; (iii) a metodologia foi capaz de fazer com que a maioria da turma participasse efetivamente da aula.

A partir dos resultados obtidos na RioSoft, decidiu-se realizar uma nova experiência no $2^{\circ}$. Semestre de 2008, na disciplina de Engenharia de Software do Curso de Bacharelado em Ciências da Computação da Universidade de Fortaleza.

No entanto, diferente da experiência anterior, optou-se por utilizar legos ao invés de quebra-cabeças, tendo em vista o lego permitir projetar, a partir de requisitos definidos, um produto a ser construído.

Outra motivação para este tipo de abordagem em sala de aula foi o professor poder realizar mais intervenções junto aos alunos e observar mais de perto as dificuldades encontradas durante a execução dos processos, percebendo assim, que conteúdos foram menos compreendidos.

A abordagem foi executada em três aulas, a turma era formada por alunos da graduação, com pouca experiência em processos e abrangeu conteúdos de cinco processos: Gerência de Projetos, Gerência de Requisitos, Garantia da Qualidade, Medição e Gerência de Configuração. Cabe ressaltar que a turma era composta apenas de alunos que estavam no final do curso e que tinham tido acesso ao conteúdo referente aos processos que iriam ser trabalhados. A experiência foi realizada em três dias, conforme descrito abaixo:

\section{Dia 1:}

No primeiro dia foi entregue a cada aluno um documento contendo o objetivo do jogo e suas regras, visto ser fundamental, em qualquer jogo, a definição de como este será conduzido e os limites de ação de cada participante (HUIZINGA, 1980) 
No referido documento ficou definido que o objetivo do jogo seria aprimorar o entendimento de alguns conceitos relacionados aos processos do MPS.BR: Gerência de Projetos, Gerência de Requisitos, Gerência de Configuração, Garantia da Qualidade e Medição.

Além disso, ficou estabelecido o seguinte: (i) cada equipe deveria montar algum objeto utilizando peças de lego; (ii) cada equipe deveria utilizar no mínimo 50 legos; (iii) cada equipe deveria ter pelo menos: 1 gerente de projetos, 2 desenvolvedores, 1 analista de medição, 1 analista da garantia da qualidade e 1 gerente de configuração; (iv) para o jogo seriam necessárias 3 aulas; (v) os membros da equipe deveriam participar de todas as 3 aulas; e (vi) não poderia haver atraso na chegada para as aulas.

Foram definidas, também, as atividades que cada grupo deveria executar. Após a apresentação do Plano das Aulas, o gerente de projetos de cada equipe elaborou o Plano do Projeto, de acordo com um modelo de documento (template) entregue pelo professor. Este modelo de documento e os demais eram os utilizados pela Instituição Implementadora do MPS.BR, UNIFOR, tendo sido realizadas modificações para que pudessem se adequar à produção de um objeto utilizando legos.

Concomitantemente o aluno "Analista de Medição" de cada projeto definiu o Plano de Medição do Projeto, contendo um único indicador com todas as características necessárias: fórmula de cálculo, forma de coleta, local de armazenamento, entre outros.

Após estas etapas, o gerente de projetos elaborou o Plano de Gerência de Configuração e o Analista de Qualidade elaborou um laudo de avaliação para o Plano do Projeto e um checklist para avaliar o processo de desenvolvimento definido no Plano de Projeto.

Finalmente, ao final da aula, o Analista da Qualidade avaliou o Plano do Projeto de acordo com os critérios que haviam sido definidos no laudo de avaliação elaborado anteriormente.

\section{* Dia 2:}

No segundo dia ocorreu a montagem do lego, de acordo com o processo definido no Plano de Projeto. Para efeito de premiação, pois a equipe que primeiro terminasse teria um bônus, todas as equipes tiveram de iniciar a montagem no mesmo instante.

Durante a construção do objeto, utilizando legos, o Analista da Qualidade avaliou a execução do processo de acordo com o checklist elaborado no primeiro dia.

Em determinado momento da execução do processo, o facilitador (professor) pediu que todas as equipes parassem, para a realização de uma reunião de acompanhamento. Esta reunião foi comandada pelo gerente de projetos, que teve de preencher um modelo de documento entregue pelo facilitador.

Um dos requisitos para esta reunião foi identificar alguma alteração de requisito. Após identificá-la, um dos desenvolvedores da equipe teve que elaborar uma solicitação de alteração de requisitos, que foi, posteriormente, analisada, do ponto de vista dos impactos e viabilidade, pelo gerente de projetos. Além disso, tal alteração deveria ter impacto no Plano do Projeto. 
Após a identificação da necessidade de alteração do referido plano, o gerente de projetos preencheu o modelo de documento próprio para a solicitação de alteração de algum item de configuração, entregando-o ao Gerente de Configuração.

Após o Gerente de Configuração ter autorizado a alteração do Plano do Projeto, este foi modificado pelo Gerente de Projeto e posteriormente versionado pelo Gerente de Configuração.

Em relação à Medição, durante a execução do processo o Analista de Medição ficou responsável por coletar o indicador que havia sido definido no Plano de Medição do Projeto.

\section{* Dia 3:}

No último dia o Analista de Medição realizou a análise do indicador, registrando o resultado em um modelo de documento entregue pelo facilitador.

Além disso, o gerente de projeto realizou a avaliação post-mortem com sua equipe, tendo capturado, anteriormente a percepção da sua equipe a partir de questionário, cujo modelo de documento foi entregue pelo facilitador.

Finalmente, ao final da última aula, o facilitador entregou um questionário para todos os alunos de forma que se conseguisse capturar a percepção deles em relação à metodologia aplicada nas últimas três aulas. $\mathrm{O}$ resultado da avaliação da metodologia aplicada, realizada pelos alunos, está detalhado na próxima seção.

\section{Avaliação da Abordagem}

Com o objetivo de verificar junto aos 27 alunos, o quanto que a abordagem auxiliou em alguns aspectos, foi elaborado um questionário contendo uma seção com questões que permitiam uma avaliação técnica da abordagem e outra onde o aluno podia avaliá-la do ponto de vista comportamental.

Para estas questões foi utilizada a Escala de Lickert, onde foram definidos os seguintes valores: Discordo Fortemente, Discordo, Nem Concordo Nem Discordo, Concordo e Concordo Fortemente. Além disso, foi solicitado que sempre que possível os alunos comentassem a avaliação de cada questão e que fossem descritos os pontos fortes, os pontos fracos e oportunidades de melhoria, de forma a poderem ser analisadas e se possível, implementadas, no próximo semestre.

A Tabela 1 apresenta a distribuição de freqüência da avaliação dos aspectos técnicos e a Tabela 2 apresenta o resultado das questões que buscaram avaliar aspectos comportamentais. Nas tabelas, DF significa "Discordo Fortemente", D significa "Discordo", NCND significa "Nem Concordo Nem Discordo", C significa "Concordo" e CF significa "Concordo Fortemente".

Tabela 1. Resultado das questões que abordam aspectos técnicos

\begin{tabular}{|c|c|c|c|c|c|}
\hline Questões & DF & D & NCND & $\mathrm{C}$ & CF \\
\hline $\begin{array}{l}\text { 1. A abordagem facilitou conhecer melhor alguns conceitos envolvidos } \\
\text { nos processos considerados durante a metodologia utilizada. }\end{array}$ & $0 \%$ & $0 \%$ & $7 \%$ & $70 \%$ & $23 \%$ \\
\hline $\begin{array}{l}\text { 2. A abordagem facilitou compreender melhor alguns conceitos que } \\
\text { foram apresentados nas aulas tradicionais ministradas pelo professor da } \\
\text { disciplina. }\end{array}$ & $0 \%$ & $0 \%$ & $3 \%$ & $81 \%$ & $6 \%$ \\
\hline
\end{tabular}




\begin{tabular}{|c|c|c|c|c|c|}
\hline $\begin{array}{l}\text { 3. A abordagem consolidou a noção que eu tenho sobre a importância, } \\
\text { para qualquer produção industrial, inclusive software, de guiar-se por } \\
\text { processos. }\end{array}$ & $0 \%$ & $3 \%$ & $22 \%$ & $45 \%$ & $30 \%$ \\
\hline $\begin{array}{l}\text { 4. A abordagem me fez enxergar melhor a importância de se ter } \\
\text { processos bem definidos. }\end{array}$ & $0 \%$ & $0 \%$ & $11 \%$ & $62 \%$ & $27 \%$ \\
\hline $\begin{array}{l}\text { 5. A abordagem permitiu que eu tivesse mais noção do quanto um } \\
\text { modelo de documento (template) bem elaborado é importante como um } \\
\text { facilitador para a execução dos processos. }\end{array}$ & $0 \%$ & $7 \%$ & $18 \%$ & $44 \%$ & $31 \%$ \\
\hline $\begin{array}{l}\text { 6. A abordagem me fez perceber a falta que um apoio automatizado } \\
\text { eficaz pode fazer para agilizar a execução das atividades. }\end{array}$ & $0 \%$ & $7 \%$ & $31 \%$ & $40 \%$ & $22 \%$ \\
\hline $\begin{array}{l}\text { 7. A abordagem me fez perceber a importância do processo ser adequado } \\
\text { ao tamanho e complexidade do projeto. }\end{array}$ & $0 \%$ & $3 \%$ & $14 \%$ & $55 \%$ & $28 \%$ \\
\hline $\begin{array}{l}\text { 8. Com este método de ensino, eu passei a conhecer melhor as } \\
\text { relações existes entre os processos tratados durante a execução da } \\
\text { abordagem. }\end{array}$ & $0 \%$ & $0 \%$ & $4 \%$ & $82 \%$ & $14 \%$ \\
\hline $\begin{array}{l}\text { 9. A abordagem me fez ter mais clara a importância de se ter os papéis e } \\
\text { responsabilidades bem definidos para a execução do processo. }\end{array}$ & $0 \%$ & $4 \%$ & $7 \%$ & $63 \%$ & $26 \%$ \\
\hline $\begin{array}{l}\text { 10. A abordagem me fez ter mais clara a importância do processo ser } \\
\text { fácil de entender para ser bem executado. }\end{array}$ & $0 \%$ & $4 \%$ & $7 \%$ & $56 \%$ & $23 \%$ \\
\hline $\begin{array}{l}\text { 11. A abordagem me fez ter mais clara a importância do processo ser } \\
\text { fácil de ser utilizado para ser bem executado. }\end{array}$ & $0 \%$ & $4 \%$ & $15 \%$ & $48 \%$ & $33 \%$ \\
\hline $\begin{array}{l}\text { 12. A abordagem me fez entender melhor a importância dos } \\
\text { envolvidos terem objetivos em comum, para a eficiência da execução } \\
\text { dos processos. }\end{array}$ & $0 \%$ & $4 \%$ & $0 \%$ & $67 \%$ & $29 \%$ \\
\hline $\begin{array}{l}\text { 13. A abordagem clareou para mim a importância de se estabelecer } \\
\text { uma boa comunicação entre os envolvidos na execução do processo, } \\
\text { para que a sua eficiência seja melhorada. }\end{array}$ & $0 \%$ & $0 \%$ & $0 \%$ & $55 \%$ & $45 \%$ \\
\hline $\begin{array}{l}\text { 14. A abordagem me fez entender melhor a relevância de um bom } \\
\text { controle gerencial para o sucesso do processo. }\end{array}$ & $0 \%$ & $4 \%$ & $4 \%$ & $59 \%$ & $23 \%$ \\
\hline $\begin{array}{l}\text { 15. A abordagem deixou mais claro para mim a importância de se ter } \\
\text { uma equipe experiente para executar o processo de maneira mais } \\
\text { eficiente. }\end{array}$ & $0 \%$ & $7 \%$ & $26 \%$ & $44 \%$ & $23 \%$ \\
\hline $\begin{array}{l}\text { 16. A abordagem me fez entender melhor a importância da } \\
\text { flexibilidade da equipe de projetos para adequar-se às mudanças } \\
\text { existentes. }\end{array}$ & $0 \%$ & $11 \%$ & $18 \%$ & $59 \%$ & $12 \%$ \\
\hline $\begin{array}{l}\text { 17. A abordagem clareou para mim o diferencial de se ter uma equipe } \\
\text { motivada para executar os processos. }\end{array}$ & $0 \%$ & $4 \%$ & $11 \%$ & $48 \%$ & $37 \%$ \\
\hline $\begin{array}{l}\text { 18. A abordagem clareou para mim a importância de se ter um ambiente } \\
\text { físico de trabalho adequado à execução do processo. }\end{array}$ & $0 \%$ & $4 \%$ & $18 \%$ & $63 \%$ & $15 \%$ \\
\hline $\begin{array}{l}\text { 19. A abordagem deixou claro para mim que implementar políticas } \\
\text { de incentivo ao uso do processo (ex.: premiações para quem tiver um } \\
\text { maior desempenho na execução do processo) pode auxiliar no } \\
\text { envolvimento dos colaboradores com os processos. }\end{array}$ & $8 \%$ & $4 \%$ & $22 \%$ & $48 \%$ & $18 \%$ \\
\hline
\end{tabular}


Tabela 2. Resultado das questões que abordam aspectos comportamentais

\begin{tabular}{|l|c|c|c|c|c|}
\hline \multicolumn{1}{|c|}{ Questões } & DF & D & NCND & C & CF \\
\hline 1. A abordagem me deixou mais à vontade em interagir com o professor. & $0 \%$ & $0 \%$ & $14 \%$ & $48 \%$ & $38 \%$ \\
\hline $\begin{array}{l}\text { 2. A abordagem me deixou mais à vontade em interagir com os } \\
\text { colegas de classe. }\end{array}$ & $\mathbf{0 \%}$ & $\mathbf{0 \%}$ & $\mathbf{7 \%}$ & $\mathbf{5 2 \%}$ & $\mathbf{4 1 \%}$ \\
\hline $\begin{array}{l}\text { 3. A abordagem me deixou mais à vontade para me colocar e fazer } \\
\text { observações. }\end{array}$ & $0 \%$ & $0 \%$ & $22 \%$ & $56 \%$ & $22 \%$ \\
\hline $\begin{array}{c}\text { 4. A abordagem proporcionou uma considerável troca de } \\
\text { experiência entre os participantes. }\end{array}$ & $\mathbf{0 \%}$ & $\mathbf{1 1 \%}$ & $\mathbf{4 \%}$ & $\mathbf{6 7 \%}$ & $\mathbf{1 8 \%}$ \\
\hline
\end{tabular}

De forma geral o resultado obtido foi bastante satisfatório, tendo sido a metodologia bem avaliada em praticamente todas as questões, visto que em todas elas, mais de $50 \%$ dos alunos concordaram ou concordaram fortemente com as afirmações.

Para uma análise dos resultados mais detalhada decidiu-se analisar as duas questões técnicas mais bem avaliadas e as duas questões que obtiveram os piores resultados. Em relação aos aspectos comportamentais resolveu-se analisar o melhor e o pior resultado. Nesta análise os melhores resultados foram computados somando as respostas "Concordo Fortemente" e "Concordo". E os piores resultados somando as respostas "Discordo" e "Discordo Fortemente".

Um resultado interessante foi que 95\% dos alunos (considerando "Concordo"e "Concordo Fortemente") acharam que a abordagem despertou neles a compreensão da relevância de se ter bons mecanismos de comunicação para a eficiência de processos de software.

Assim como também, 96\% dos alunos (considerando "Concordo" e "Concordo Fortemente") acharam que passaram a conhecer melhor as relações existes entre os processos Gerência de Projetos, Gerência de Requisitos, Gerência de Configuração, Garantia da Qualidade e Medição. Este resultado foi muito importante, pois em apenas três aulas a interação entre os processos foi mais compreendida por eles, diferentemente das aulas teóricas, onde é sempre muito mais difícil perceber os pontos de interligação entre os processos.

Semelhante ao resultado anterior, 96\% deles colocaram que a abordagem permitiu um melhor entendimento da importância de todos estarem com objetivos em comum, ou seja, de todos estarem comprometidos com a implantação e execução de processos na organização.

Em relação aos piores resultados, pudemos observar que para $12 \%$ dos alunos (considerando "Discordo" e "Discordo Fortemente"), a abordagem ainda não foi suficientemente capaz de tornar claro para eles, a relevância de se implementar políticas de incentivo ao uso do processo para melhorar o nível de envolvimento e comprometimento dos colaboradores.

Além disso, 11\% deles (considerando "Discordo" e "Discordo Fortemente") acharam que a abordagem ainda não foi suficientemente eficaz para melhorar o nível de compreensão dos alunos em relação à existência de uma equipe flexível ser um dos fatores de sucesso para a execução de processos de software. Este resultado foi 
intrigante, pois alguns alunos fizeram este tipo de avaliação mesmo havendo situações de alterações de requisitos e monitoração de projetos.

De acordo com os resultados das questões comportamentais, observamos que 93\% dos alunos (considerando "Concordo" e "Concordo Fortemente") acharam que a abordagem os deixou mais à vontade com os seus colegas. Analisando este aspecto como um facilitador da dinâmica e que também vivenciou esta experiência, pôde-se perceber que esta abordagem pode ser utilizada também como um meio de entrosamento entre alunos.

No entanto, $11 \%$ deles discordaram de que a abordagem propiciou uma troca de experiência entre os participantes. Tal resultado talvez se deve ao fato de que quase todos eles não tinham experiência prática na execução de processos.

Os alunos ainda consideraram como principal ponto fraco, o tempo estabelecido para realizar a metodologia, ou seja, os três dias que foram definidos. Além deste, o fato de alguns alunos não encararem a experiência com seriedade. Em relação aos pontos fortes, foram colocados os seguintes: a possibilidade de aumentar o nível de interação ente os alunos e aluno/professor e o auxílio que a abordagem oferece para consolidar conceitos, a partir da vivência da teoria. Quanto às oportunidades de melhoria, destacaram-se: aumentar o tempo de execução da abordagem e definir o mesmo projeto para todas as equipes, permitindo melhorar as análises e comparações.

\section{Considerações Finais}

A execução da abordagem mostrou-se eficaz em vários aspectos, como se pôde observar pelo resultado da pesquisa. No entanto, muitas oportunidades de melhoria merecem ser implementadas em próximas experiências. Dentre elas, a principal será aumentar o tempo de execução da abordagem para que o preenchimento dos modelos de documentos seja realizado com um melhor nível de qualidade, a partir de uma maior reflexão. Outra possível alteração é intercalar as aulas teóricas com as aulas práticas, onde o professor possa refletir com os alunos os fatos e dificuldades mais relevantes que ocorreram.

\section{Referências}

Popper, K. R. (1996), O Mito do Contexto: Em defesa da ciência e da racionalidade, Edições 70, Lisboa.

SOFTEX (2007) "Melhoria de Processo de Software Brasileiro - Guia Geral versão 1.2", http://www.softex.br/mpsbr.

Mora, J. F. (1991), Dicionário de Filosofia, Publicações Dom Quixote, Lisboa.

Popper, K. R. (1972), A Lógica da Pesquisa Científica, Editora Cultrix, São Paulo.

Dewey, J. (1979), Como Pensamos, Editora Nacional, São Paulo.

Moles, A. (1998), A Criação Científica, Editora Perspectiva, São Paulo.

Huizinga, J. (1980), Homo Ludens, Editora Perspectiva, São Paulo. 